\title{
Anxiety disorders seen in primary care
}

TERRY M. BROWN, DO DAVID A. BARON, DO

This paper presents a clinical overview of syndromal anxiety and its treatment as seen in a family practice setting, where many patients with anxiety disorders are first seen. Panic disorder, social phobia, agoraphobia, and generalized anxiety disorder are the ones most often seen by such physicians. Treatment options include psychotherapy, behavioralcognitive therapy, and pharmacotherapy. The primary care physician may choose from the benzodiazepines or the heterocyclic antidepressants or both. The monoamine oxidase inhibitors have also proved very useful in the treatment of panic disorder and social phobia, but probably should be used only by physicians with experience with this type of medication.

(Key words: Panic disorder, social phobia, generalized anxiety disorder, posttraumatic stress disorder, obsessive-compulsive disorder, major depression, antidepressant, $\beta$-blocker, neuroleptic, alprazolam, phenelzine, buspirone, fluoxetine, imipramine, desipramine, clonazepam)

\footnotetext{
At the time this paper was written, Dr Brown was senior medical staff fellow, National Institute of Mental Health, Biological Psychiatry Branch, Section on Anxiety and Affective Disorders, National Institute of Mental Health, Intramural Research Program, Bethesda, Md.

Dr Baron is Deputy Elinical Director, National Institute of Mental Health, Intramural Research Program, Bethesda, Md.

Reprint requests to Terry M. Brown, DO, Department of Psychiatry and Health Behavior, Medical College of Georgia, 1515 Pope Ave, Augusta, GA 30912.
}

Recent epidemiologic surveys have revealed that primary care physicians see more patients with anxiety and depression than with diabetes or asthma, and commonly see more than one patient per day suffering from anxiety disorders. ${ }^{1,2}$ Anxiety can present as a primary pathologic condition, a comorbid problem, or can exacerbate underlying medical illness. Anxiety disorders can appear as discrete symptoms, or as full-blown syndromal dysfunction. $\mathrm{Pa}$ tients having these problems typically go to their family practitioner, not a psychiatrist, with somatic complaints ${ }^{3}$ (cardiovascular, gastrointestinal,${ }^{4}$ musculoskeletal) that are easily misdiagnosed. The clinician should first rule out organic disease but be sensitive to the role that anxiety may play in primary care medicine.

Most patients will not discuss their psychic complaints, either failing to appreciate the importance of these problems, or believing it inappropriate to discuss emotional concerns with their family physicians. Patients often are reluctant to "air their dirty laundry," feeling that admitting to emotional symptoms is tantamount to a "flaw in one's moral fiber." For these reasons, it is imperative that the family practice physician actively solicit information about the patient's emotional state, clarifying the importance of this information in developing an accurate differential diagnosis and effective treatment strategy. General practitioners are routinely at the front lines of assessment, often being the first and only access to appropriate care.

For accurate diagnosis and treatment of 
these conditions, the clinician must know what to look for. Evaluation, as in all clinical medicine, begins with a baseline history and physical examination. A psychosocial history should be included in each office visit. Although a number of validated psychometric instruments are available for screening of office patients, one should never rely on the results of a pencil-andpaper test to diagnose anxiety or depressive disorders. Similarly, no biologic marker has proved to be of significant clinical usefulness in diagnosing these conditions. An accurate diagnosis is made by listening to the patient and eliciting information about specific characteristic symptom clusters, allowing a discrete diagnosis and treatment plan to be developed.

The anxiety disorders defined by the Diagnostic and Statistical Manual of Mental Disorders, third edition, revised $(D S M-I I I-R)^{5}$ include panic disorder, agoraphobia, social phobia, generalized anxiety disorder, simple phobia, obsessive-compulsive disorder, and posttraumatic stress disorder. The present discussion will emphasize the first four disorders, those most commonly seen in a primary care setting.

\section{Panic disorder}

\section{Diagnosis}

The DSM-III- $R^{5}$ defines panic disorder as involving one or more discrete periods of intense fear or discomfort of an unexpected nature, not triggered by the patient's being the object of social scrutiny. Frequency criteria include the requirement for either four panic attacks in a 4-week period, or the occurrence of one or more panic attacks with at least a month of persistent worry of having another attack. According to DSM-III-R, ${ }^{5}$ at least four of the following autonomic symptoms are required for the panic attack:

- difficulty breathing, shortness of breath;

- feelings of depersonalization or derealization;

- nausea or other gastrointestinal distress;

- a feeling of doom or imminent death;

- palpitations and tachycardia;

- sweating;

- tremor and shaking;

- choking sensations;

- paresthesia;
- fear of losing control and going crazy;

- flushes, feeling hot, or chills;

- chest pain or chest discomfort (can mimic angina);

- dizziness, faintness, fear of fainting.

Less than four symptoms are considered limited-symptom panic attacks. Panic attacks often develop over a period of 10 minutes, and may last from 15 to 20 minutes to several hours. Patients may have a history of going to emergency rooms with chest pain and other somatic symptoms, only to have normal findings on an electrocardiogram. They often calm down with reassurance and benzodiazepines. A subset of these patients may be labeled as having hyperventilation episodes, but it is not certain whether the hyperventilation is the cause or the result of the panic episode. .-11 $^{-1}$

Once organic factors have been ruled out, the diagnosis can be made. Panic attacks can be related to cocaine, phencyclidine hydrochloride (PCP), or occasionally marijuana use, and these panic attacks can persist for years beyond the cessation of substance abuse. Other organic conditions that should be ruled out include pheochromocytoma, carcinoid syndrome, respiratory illnesses such as chronic obstructive pulmonary disease (COPD) and asthma, cardiac arrhythmia, and myocardial infarction. Mitral valve prolapse has been associated with panic disorder as well, ${ }^{12,13}$ but the relationship remains controversial.

Panic disorder may be uncomplicated or be associated with agoraphobia (literally, "fear of the market place"). If panic attacks are associated with certain stimuli such as shopping in the supermarket, flying, riding the subway or bus, or driving the car, these activities may be avoided to one degree or another. ${ }^{14}$ Some persons become totally housebound and may not seek treatment. Rarely, people come for treatment who have significant agoraphobia but do not recall a clear history of panic attacks.

\section{Treatment}

Behavioral treatments such as systematic desensitization via hierarchical imagery or in vivo treatments have been helpful in treating agoraphobic symptoms. ${ }^{15}$ Usually, the panic at- 
tacks themselves do not respond to this type of treatment, particularly when the panic attacks have the typical "out-of-the-blue" onset. One nonpharmacologic treatment has included breathing retraining with use of a metronome to pace respiratory rate. Though still unproved, such treatment may be helpful for those patients who hyperventilate readily. ${ }^{6} \mathrm{Re}-$ laxation training has also been helpful, but paradoxically can make some patients have panic attacks. Some patients have exerciseinduced panic attacks as well, and these patients may be very sensitive to the hypocapnia that can develop with an increase in minute ventilation. ${ }^{16}$

Much has been written about the behavioral and pharmacologic treatment of panic disorder, with pharmacologic treatment being the mainstay. ${ }^{17-20}$ One may choose from the antidepressants $^{21-26}$ or the benzodiazepines or both. ${ }^{27}$ The benzodiazepine that may be the most effective, and is the best studied in the treatment of panic disorder, is alprazolam (Xanax). ${ }^{28-30}$ Alprazolam is a triazolobenzodiazepine that some clinicians have suggested is relatively specific for panic disorder in comparison to other benzodiazepines, ${ }^{31}$ although comparisons between alprazolam and other benzodiazepines have been difficult to interpret because of noncomparable dosing. Alprazolam is the only medication that has a Food and Drug Administration (FDA) indication for the treatment of panic disorder. ${ }^{28}$ This drug has received a great deal of bad press (Washingtonian, April 1990). Patients and their physicians are often overly concerned about addictive potential; as a result, some patients have been treated with homeopathically low doses that are ineffective. In most persons, 5 $\mathrm{mg} / \mathrm{d}$ to $6 \mathrm{mg} / \mathrm{d}$ is required to remit the panic symptoms. ${ }^{31}$ Fears of endless tolerance are generally groundless. Some persons who have a history of recreational drug use may be at greater risk for abuse; for these persons, heterocyclic antidepressants in general are preferable.

Most patients will have some difficulty withdrawing from alprazolam ${ }^{32-34}$ unless the withdrawal is undertaken in a very gradual manner, such as by decreasing the dose by 0.25 mg every week to 10 days. Abrupt withdrawal has produced significant side effects and rarely seizures. ${ }^{35-38}$ However, in the Cross National Study, ${ }^{39-41}$ which involved a large number of patients at multiple sites, withdrawal at the rate of $0.5 \mathrm{mg}$ per week resulted in no seizures or other significant side effects. Rebound anxiety and recurrence of panic attacks are the most common symptoms. Adding carbamazepin $\mathrm{e}^{42,43}$ before withdrawing the alprazolam may be helpful, although this drug is not particularly effective in treating the panic disorder itself. ${ }^{44}$ Some have substituted the longer half-life benzodiazepine clonazepam with success. ${ }^{45}$ Patients may need to continue taking alprazolam longer than the FDA's recommended 12 weeks. ${ }^{28}$ Often during times of low psychosocial stress, the dosage may be tapered more easily.

The other pharmacologic agents for treatment of panic disorder are the antidepressants $^{46}$ including the heterocyclic antidepressants and the monamine oxidase inhibitors. Some investigators have suggested that monoamine oxidase inhibitors might be slightly more effective than imipramine, ${ }^{31}$ but they are the least used because of the need for the patient to avoid foods containing tyramine. Failure to avoid such foods can result in a severe hypertensive reaction. Although the risk of significant side effects is low, most nonpsychiatric practitioners should refer patients to psychiatrists familiar with the use of these drugs, if other treatments have failed.

The heterocyclic antidepressants should be used as they would in the treatment of depression. ${ }^{21}$ However, the treatment response may occur at a dose lower than $150 \mathrm{mg}$, or with serum levels less than $150 \mathrm{ng} / \mathrm{mL}$. Indeed, patients with panic disorder seem to be more sensitive to the side effects of heterocyclic antidepressants than are depressed persons. Early in the course of treatment, they may have the so-called jitters, which paradoxically seems to be an increase in their general anxiety level. ${ }^{47}$ Titration must go slowly and often starts at $10 \mathrm{mg} / \mathrm{d}$ to $25 \mathrm{mg} / \mathrm{d}$, with gradual increases of $10 \mathrm{mg}$ to $25 \mathrm{mg}$ weekly. Response to heterocyclic antidepressants takes longer than the 
response to alprazolam. Often, to keep the patient in treatment, small doses of alprazolam ( $1 \mathrm{mg} / \mathrm{d}$ to $2 \mathrm{mg} / \mathrm{d}$ ), can be used initially with the heterocyclic agent to ameliorate this initial medication-related-anxiety. Then, once the patient is stabilized on the heterocyclic antidepressant regimen, dosage of alprazolam can be tapered and the benzodiazepine used on an as-needed basis at low dose (less than $1 \mathrm{mg} / \mathrm{d}$ ) when patients must expose themselves to situations that cause anxious feelings, such as getting on a plane or going to the mall. As in the treatment of depression, one cannot be sure that the patient having panic has had an adequate trial with the drug unless a dose of $150 \mathrm{mg}$ or higher has been reached.

The most commonly used and best studied tricyclic antidepressant is imipramine (Tofranil). Some evidence indicates that imipramine's metabolite desipramine (Norpramin) may work just as well, and it is better tolerated. Other tricyclic antidepressants probably are effective, though clinical trials have been fewer in number. The new antidepressant fluoxetine (Prozac), according to an early report, ${ }^{48}$ appears effective in treating panic disorder, but additional double-blind clinical trials are needed to confirm its efficacy. Many patients having panic disorder cannot initially tolerate the $20-\mathrm{mg}$ pulvule, which is the only size manufactured. Patients often complain of the jitters on this dose. Alternatively, a liquid form of fluoxetine $(20 \mathrm{mg} / \mathrm{mL})$ is now available, allowing more gradual titration of dosage increase (PDR Supplement 1991). Dosage for most patients should not increase above 20 $\mathrm{mg}$ to $60 \mathrm{mg}$ daily, on the basis of our present knowledge.

In early 1990 , Teicher and coworkers ${ }^{49}$ reported several case studies in which it appeared that depressed patients who were started on fluoxetine therapy developed suicidal ideation and intent. No causal relationship has been proved, and it should be kept in mind that depressed patients are far more likely to have suicidal ideation than those patients who are not depressed. Recently, the FDA $^{50}$ reviewed the matter and concluded that there was no need to revise fluoxetine's labeling on the basis of present evidence.
Patients may need to take the antidepressant for 6 to 12 months. The clinician must be aware of the potential for relapse, which may be greater than that observed in the treatment of depression. Patients should be advised to significantly decrease their caffeine consumption as methylxanthines, including most asthma medications, lower the threshold for panic. Indeed, caffeine at $480 \mathrm{mg}$ by mouth (approximately equivalent to 4 to 5 cups of coffee) has been used to induce panic attacks in various research protocols. ${ }^{51-59}$ In many cases, the use of asthma medications necessitates a higher dose of alprazolam. $\beta$-Blockers ${ }^{60}$ and buspirone hydrochloride ${ }^{61-66}$ do not appear to be effective in the treatments of panic disorder, although the latter may have some usefulness in the treatment of generalized anxiety disorder.

\section{Generalized anxiety disorder}

Generalized anxiety disorder is characterized by persistent, nondiscrete anxiety such that the person worries about two or more life circumstances on a daily basis. Autonomic symptoms may persist but usually are less severe than in panic disorder. In general, alprazolam or heterocyclic antidepressants or both are used to treat this condition. Psychotherapy alone rarely may be effective.

Neuroleptics generally have no place in the treatment of the anxiety disorders because of the risk of significant side effects such as parkinsonian-like symptoms, ${ }^{67(p p 1411-1417)}$ neuroleptic malignant syndrome ${ }^{67(p p 1421-1430), 68}$ (a febrile illness with elevated creatinine phosphokinase, rhabdomyolosis, and potential renal failure), and tardive dyskinesia (involving choreoathetoid movements, tremor, and occasionally significant disability). ${ }^{67(p p 1411-1417)}$

The practitioner should be wary of the use of combination products that contain a tricyclic antidepressant and a neuroleptic (Triavil). It is perhaps a misnomer to refer to the neuroleptics as major tranquilizers, because this reference suggests that they be used in the treatment of anxiety disorders. Rarely they are useful, in low dose, in the treatment of psychoticlike symptoms associated with anxiety disorders. The practitioner should exercise extreme caution when prescribing these drugs, with fre- 
quent evaluation of dosage and side effects.

\section{Social phobia}

The anxiety disorder called social phobia deserves special comment. It is an underdiagnosed syndrome ${ }^{69}$ often being erroneously perceived as simple shyness. Social phobia is not ordinary shyness, however, but one that extensively interferes with social and occupational functioning. In social phobia, the primary fear is that one will be scrutinized and evaluated negatively. Some fear they will say something stupid, or act in some embarrassing or humiliating manner in front of others.

Common fears concern having others watch one eating or giving a speech, fear about using public restrooms, or fear of hand trembling while writing a check or filling out forms. There is the generalized type, and the more specific type. The latter usually relates to one specific fear such as public speaking and becomes a problem when the patient's job suddenly requires this action. Social phobic avoidance is unlike agoraphobia, because, in the latter, the person is concerned about having a panic attack in a public place and not being able to get help. In agoraphobia, embarrassment may be present, but it is not primary. With the social phobic, scrutiny and embarrassment are key issues, and not the fear of having a panic attack.

A frequent treatment for social phobia has been in vivo desensitization ${ }^{15}$ to phobic social stimuli (toastmasters, for example). This is particularly useful for specific public-speaking fears. Some persons have so much phobic avoidance they cannot be coaxed into exposure therapy. It may be that most persons with social phobia never seek treatment, as many are fearful around authority figures such as physicians and clergy.

Medication is often helpful in allowing patients to expose themselves to these stimuli without fears of trembling, sweating, heart racing, et cetera. $\beta$-Blockers are helpful in decreasing the autonomic symptoms associated with social anxiety ${ }^{70,71}$ Effective dosage is $20 \mathrm{mg}$ to $80 \mathrm{mg}$ of propranolol a couple of hours before a social situation. Alprazolam and the monoamine oxidase inhibitor phenelzine (Nar- dil) $)^{72,73}$ have also shown some efficacy. Once exposure to certain social situations becomes routine, the medicine may be decreased, or discontinued entirely. Novel social stressors, however, may necessitate reinstitution of the medicine. Heterocyclic antidepressants are not known to be helpful in social phobia, unless there is a primary or secondary major depression associated with the social phobic symptoms. Pharmacologic treatment for simple phobia generally is unnecessary, and exposure desensitization methods are preferred.

The foregoing discussion has referred to primary anxiety disorders. Often, anxiety symptoms such as panic attacks, obsessions, and even social fears overlap with symptoms of major depression. These disorders can coexist with major depression, but frequently the depression is secondary, and often in the case of panic disorder and agoraphobia is referred to as a "demoralization" type of depression. ${ }^{74}$ The latter nevertheless can be quite severe. Alternatively, a primary major depression can be accompanied by panic attacks or other anxiety symptoms. In both of these clinical situations, antidepressants, and perhaps benzodiazepines, may be indicated for the symptomatic treatment of anxiety and depression. The term antidepressant is based on the initial historical indication of these drugs, and the effective management of anxiety disorders with an antidepressant does not imply that the patient is clinically depressed. The antidepressant will treat the patient's anxiety regardless of whether he or she is depressed.

\section{Comment}

The primary care physician is the first, and sometimes the only, physician to encounter a variety of patients with diverse anxiety symptoms. Many patients have elements of several of the anxiety disorders. For example, a patient with spontaneous panic attacks may also have a specific social or other phobia. Also, many patients have transient or mild symptoms, or both, but fall short of meeting the $D S M-I I I-R$ criteria. Many of the latter may be treated successfully with counseling. The patients with more serious and chronic symptoms may require medication in addition to 
counseling. When in doubt, a psychiatric consultation may help clarify diagnostic or treatment or both issues.

\section{References}

1. McGlynn TS, Metcalf AL (eds): Diagnosis and Treatment of Anxiety Disorders: A Physician's Handbook. Washington, DC, American Psychiatric Press, Inc, 1987.

2. Katon W: Panic disorder: Epidemiology, diagnosis, and treatment in primary care. $J$ Clin Psychiatry 1986;47(suppl):21-30.

3. Katon W, Vitaliano PP, Russo J, et al: Panic disorder: Epidemiology in primary care. J Fam Pract 1986;23:233-239.

4. Noyes R Jr, Cook B, Garvey M, et al: Reduction of gastrointestinal symptoms following treatment for panic disorder. Psychosomatics 1990;31:75-79.

5. Diagnostic and Statistical Manual of Mental Disorders DSM$I I I-R$, ed 3, rev. Washington, DC, American Psychiatric Press, Inc, 1987, P 235-253.

6. Gorman JM, Askanazi J, Liebowitz MR, et al: Response to hyperventilation in a group of patients with panic disorder. Am J Psychiatry 1984;141:857-861.

7. Gorman JM, Uy J: Respiratory physiology and pathological anxiety. Gen Hosp Psychiatry 1987;9:410-419.

8. Gorman JM, Fyer MR, Goetz R, et al: Ventilatory physiology of patients with panic disorder. Arch Gen Psychiatry 1988;45:139.

9. Papp LA, Martinez JM, Klein DF, et al: Arterial blood gas changes in panic disorder and lactate-induced panic. Psychiatry Res 1989;28:171-180.

10. Neill WA, Hattenhauer M: Impairment of myocardial $0_{2}$ supply due to hyperventilation. Circulation $1975 ; 52: 854-858$.

11. Gorman JM, Fyer AJ, Ross DC, et al: Normalization of venous $\mathrm{pH}, \mathrm{pCO}_{2}$, and bicarbonate levels after blockade of panic attacks. Psychiatry Res 1985;14:57-65.

12. Gorman JM, Shear MK, Devereaux RB, et al: Prevalence of mitral valve prolapse in panic disorder: Effect of echocardiographic criteria. Psychosom Med 1986;48:167-171.

13. Gorman JM, Goetz RR, Fyer M, et al: The mitral valve prolapse-panic disorder connection. Psychosom Med 1988;50:114122.

14. Klein DF, Gorman JM: A model of panic and agoraphobic development. Acta Psychiatr Scand 1987;76(suppl 335):87-95.

15. Hersen M (ed): Outpatient Behavior Therapy: A Clinical Guide. Orlando, Fla, Grune \& Stratton, 1983, pp 58-72.

16. Gorman JM, Liebowitz MR, Fyer AJ, et al: Possible respiratory abnormalities in panic disorder. Psychopharmacol Bull 1986;22:797-801.

17. Zitrin CM, Klein DF, Woerner MG: Behavior therapy, supportive psychotherapy, imipramine and phobias. Arch Gen Psychiatry 1978;35:307-316.

18. Zitrin CM, Klein DF, Woerner MG: Treatment of agoraphobia with group exposure in vivo and imipramine. Arch Gen Psychiatry 1980;37:63-72.

19. Zitrin CM: Combined pharmacological and psychological treatment of phobias, in Mavissakalian M, Barlow DH (eds): Phobia: Psychological and Pharmacological Treatments New York, NY, Guilford Press, 1981.

20. Zitrin CM, Klein DF, Woerner MG: Treatment of phobias. I: Comparison of imipramine hydrochloride and placebo. Arch Gen Psychiatry 1983;40:125-138.

21. Liebowitz MR, Fyer AJ, Gorman JM, et al: Tricyclic ther- apy of the DSM-III anxiety disorders: A review with implications for further research. J Psychiatr Res 1988;22(suppl 1):731, 1988.

22. Aronson TA: A naturalistic study of imipramine in panic disorder and agoraphobia. Arch Gen Psychiatry 1987;144:10141019.

23. Jobson K, Linnoila LM, Gillam J, et al: Successful treatment of severe anxiety attacks with tricyclic antidepressants: A potential mechanism of action. Am J Psychiatry 1978;135:863864 .

24. Nurnberg MG, Copccaro EF: Response of panic disorder and resistance of depression to imipramine. Am $J$ Psychiatry 1982;139:1060-1061.

25. Rifkin A: Clinical and psychobiologic implications of response to tricyclic antidepressants in patients without primary affective disorder. Psychopharmacol Bull 1983;19:432-434.

26. Sheehan DV, Ballenger J, Jacobson G: Treatment of endogenous anxiety with phobic, hysterical, and hypochondriacal symptoms. Arch Gen Psychiatry 1980;37:51-57.

27. Noyes R Jr, Anderson DJ, Clancy J, et al: Diazepam and propranolol in panic disorder and agoraphobia. Arch Gen Psychiatry 1984;41:287-292.

28. FDA committee recommends Xanax for treatment of panic attacks. Drug Therapy, December 1989, p 45.

29. Rickels K, Csanalosi I, Greisman P, et al: A controlled clinical trial of alprazolam for the treatment of anxiety. Am J Psychiatry 1983;140:82-85.

30. Liebowitz MR, Fyer AJ, Gorman JM, et al: Alprazolam in the treatment of panic disorders. $J$ Clin Psychopharmacol 1986;6:13-20.

31. Uhde TW, Nemiah JC: Anxiety disorders (anxiety and phobic neuroses), in Kaplan HI, Saddock BJ (eds): Comprehensive Textbook of Psychiatry, ed 5. Baltimore, Md, Williams \& Wilkins, 1989, pp 952-972.

32. Fyer AJ, Liebowitz MR, Gorman JM, et al: Discontinuation of alprazolam treatment in panic patients. Am J Psychiatry 1987; 144:303-308.

33. Mellman TA, Uhde TW: Withdrawal syndrome with gradual tapering of alprazolam. Am J Psychiatry 1986;143:14641466.

34. Roy-Byrne PP, Dager SR, Cowley DS, et al: Relapse and rebound following discontinuation of benzodiazepine treatment of panic attacks: Alprazolam versus diazepam. Am J Psychiatry 1989;146:860-865.

35. Noyes R, Clancy J, Coryell WH, et al: A withdrawal syndrome after abrupt discontinuation of alprazolam. Am J Psychiatry 1986;149:235-238.

36. Warner MD, Peabody CA, Boutros NN, et al: Alprazolam and withdrawal seizures. J Nerv Ment Dis 1990;178:208-209.

37. Naylor MW, Grunhaus L, Cameron O: Myoclonic seizures after abrupt withdrawal from phenelzine and alprazolam $J$ Nerv Ment Dis 1987:175:111-114.

38. Brown JL, Hauge KJ: A review of alprazolam withdrawal. Drug Intell Clin Pharm 1986;20:837-841.

39. Ballenger JC, Burrows GD, DuPont RL, et al: Alprazolam in panic disorder and agoraphobia: Results from a multicenter trial: I. Efficacy in short-term treatment. Arch Gen Psychiatry 1988;45:413-422.

40. Noyes R, DuPont RL, Pecknold JC, et al: Alprazolam in panic disorder and agoraphobia: Results from a multicenter trial: II. Patient acceptance, side effects, and safety. Arch Gen Psychiatry 1988;45:423-428.

41. Pecknold JC, Swinson RP, Kuch K, et al: Alprazolam in panic disorder and agoraphobia: Results from a multicenter 
trial. III. Discontinuation effects. Arch Gen Psychiatry 1988;45:429-436.

42. Klein E, Uhde TW, Post RM: Preliminary evidence for the utility of carbamazepine in alprazolam withdrawal. Am J Psychiatry 1986;143:235-236.

43. Ries RK, Roy-Byrne PP, Ward NG, et al: Carbamazepine treatment for benzodiazepine withdrawal. Am J Psychiatry 1989;146:536-537.

44. Uhde TW, Stein MB, Post RM: Lack of efficacy of carbamazepine in the treatment of panic disorder. Am $J$ Psychiatry 1988;145:1104-1109.

45. Albeck JH: Withdrawal and detoxification from benzodiazepine dependence: A potential role for clonazepam. J Clin Psychiatry 1987;48(suppl):43-49.

46. McNair DM, Kahn EJ: Imipramine vs a benzodiazepine for agoraphobia, in Klein DF, Rabkin J (eds): New Research and Changing Concepts. New York, NY, Raven Press, 1981, pp 6980.

47. Pohl R, Yeragani VK, Balon R, et al: The jitteriness syndrome in panic disorder patients treated with antidepressants. $J$ Clin Psychiatry 1988;49:100-104.

48. Gorman JM, Liebowitz MR, Fyer AJ, et al: An open trial of fluoxetine in the treatment of panic attacks. J Clin Psychopharmacol 1987 Oct;7:329-332 (erratum Feb 1988;8:13).

49. Teicher MH, Glod C, Cole JO: Emergence of intense suicidal preoccupation during fluoxetine treatment. Am J Psychiatry 1990;147:207-210.

50. Talk Paper: Antidepressant update. Food and Drug Administration, Rockville, Md, US Department of Health and Human Services, Department of Health Services, 1991.

51. Uhde TW, Boulenger J-P, Vittone B, et al: Caffeine: Relationship to human anxiety, plasma MHPG and cortisol. Psychopharmacol Bull 1984;20:426-430.

52. Uhde TW, Boulenger J-P: Caffeine model of panic, in Lerer B, Gershon S (eds): New Directions in Affective Disorders. New York, NY, Springer-Verlag, 1989, pp 410-413.

53. Uhde TW: Caffeine: Practical facts for the psychiatrist, in Roy-Byrne PP (ed): New Findings for the Clinician. Washington, DC, American Psychiatric Press, Inc, 1988, pp 73-98.

54. Uhde TW: Caffeine provocation of panic: A focus on biological mechanisms, in Ballenger JC (ed): Neurobiological Aspects of Panic Disorder (Frontiers of Clinical Neuroscience). New York, NY, Alan R. Liss, 1990, pp 219-241.

55. Boulenger J-P, Uhde TW: Caffeine consumption and anxiety: Preliminary results of a survey comparing patient with anxiety disorders and normal controls. Psychopharmacol Bull 1982;18:53-57.

56. Boulenger J-P, Bierer LM, Uhde TW: Anxiogenic effects of caffeine in normal controls and patients with panic disorder, in Shagass C, Josiassen WH, Bridger WH, et al (eds): Biological Psychiatry 1985. New York, NY, Elsevier Science Publishing $\mathrm{Co}, 1986$, pp 454-456.
57. Boulenger JP, Uhde TW, Wolff EA, et al: Increased sensitivity to caffeine in patients with panic disorders, preliminary evidence. Arch Gen Psychiatry 1984;41:1067-1071.

58. Greden JF: Anxiety or caffeinism: A diagnostic dilemma. Am J Psychiatry 1974;131:1089-1092.

59. Uhde TW, Tancer ME: Chemical models of panic: A review and critique, in Tyrer P (ed): Psychopharmacology of Anxiety, London, England, Oxford University Press, 1989, pp 109131.

60. Munjack DJ, Crocker B, Cabe D, et al: Alprazolam, propranolol, and placebo in the treatment of panic disorder and agoraphobia with panic attacks. J Clin Psychopharmacol 1989;9:2227.

61. Sheehan DV, Raj AB, Sheehan KH, et al: Is buspirone effective for panic disorder? J Clin Psychopharmacol 1990;10:3-11.

62. Gastfriend DR, Rosenbaum JF: Adjunctive buspirone in benzodiazepine treatment of four patients with panic disorder. Am $J$ Psychiatry 1989;146:914-916.

63. Fuller RW: Buspirone metabolite and panic attacks, letter. Lancet 1990;335(8687):470.

64. Robinson DS, Shrotriya RC, Alms DR, et al: Treatment of panic disorder: Nonbenzodiazepine anxiolytics, including buspirone. Psychopharmacological Bull 1989;25:21-26.

65. Norman TR, Judd FK: Panic attacks, buspirone, and serotonin function (letter). Lancet 1989;2(8663):615.

66. Sheehan DV, Raj AB, Sheehan $\mathrm{KH}$, et al: The relative efficacy of buspirone, imipramine, and placebo in panic disorder: A preliminary report. Pharmacol Biochem Behav 1988;294:815817.

67. Meltzer HY (ed): Psychopharmacology: The Third Generation of Progress. New York, NY, Raven Press, 1987, pp 1411. 1419.

68. Ebadi M, Pfeiffer RF, Murrin LC: Pathogenesis and treatment of neuroleptic malignant syndrome. Gen Pharmacol 1990;21:367-386.

69. Liebowitz MR, Gorman JM, Fyer AJ, et al: Social phobia: Review of a neglected anxiety disorder. Arch Gen Psychiatry 1985;42:729-736.

70. Liebowitz MR, Gorman JM, Fyer AJ, et al: Pharmacotherapy of social phobia: An interim report of a placebo-controlled comparison of phenelzine and atenolol. J Clin Psychiatry 1988;49:252-257.

71. Gorman JM, Liebowitz MR, Fyer AJ, et al: Treatment of social phobia with atenolol. J Clin Psychopharmacol Oct $1985 ; 298-301$

72. Liebowitz MR, Fyer AJ, Gorman JM, et al: Phenelzine in social phobia. J Clin Psychopharmacol April 1986;6:93-98.

73. Gorman JM, Gorman LK: Drug treatment of social phobia. $J$ Affective Disord Sept-Oct 1987;13:183-192.

74. Stein MB, Uhde TW: Panic disorder and major depression: A tale of two syndromes. Psychiat Clin North Am 1988;11:441461. 